\title{
ИСТОРИЯ ОТКРЫТИЯ «МАНТИЙНОГО» ГЕЛИЯ (50 ЛЕТ С МОМЕНТА ПЕРВЫХ ИЗМЕРЕНИЙ В ГАЗАХ КУРИЛ)
}

\author{
Каменский И.Л. \\ Геологический институт КНЦ РАН, Anamumb, iglkam@mail.ru
}

«Один опыт - не опыт, два опыта - закон, три опыта - статистика» (правило для физиков-экспериментаторов)

Поводом для этой статьи послужила информация из очень авторитетного европейского журнала - Geochemical Perspectives [9]. В ней утверждаются два положения, которые мне кажутся ошибочными и требующими уточнения и обсуждения: 1) Холодная война - причина, почему западные ученые «забыли» достижения советских ученых; 2) Измерения ${ }^{3} \mathrm{He} /{ }^{4} \mathrm{He}$ для пород мантии в океанических базальтах были выполнены в СССР для образцов Крылова А.Я. [1], а не Эрлиха Е.Н., т. к. ксенолиты, отобранные на поверхности, наверняка содержали «космогенный» гелий. В краткой форме про историю открытие мантийного гелия было изложено в тезисах для совещания в Китае в 1998 г. [8]. Эта публикация в какой-то мере сыграла свою роль, т. к. в статье [7] уже правильно сказано, что первозданный гелий, поступающий из мантии, был открыт в вулканических газах и океанической воде. По объектам исследования (1 - спонтанные газы горячих ключей Курил и 2 - газы, растворенные в воде Тихого океана) последовательность аналитических достижений и дат выхода публикаций приведена правильно. Но Б.А. Мамырин, автор статьи про газы Курил, в ссылках на публикации оказался вторым, а В.Б. Кларк, который занимался изучением воды Тихого океана, по какой-то причине стоит первым. Поэтому у читателя может сложиться представление, что приоритет в открытии мантийного гелия принадлежит В.Б. Кларку, а Б.А. Мамырин это подтвердил. Все наоборот. Наша публикация была принята в печать в июле 1968 г. и вышла в мае 1969 г. Статья В.Б. Кларка в мае 1969 г. только поступила в редакцию и хотя вышла очень быстро в сентябре 1969 г., но все же после нашей.

История открытия мантийного гелия в СССР началась в 1965 г. в Ленинграде, когда И.Н. Толстихин рассказал мне и Э.М. Прасолову, каким интереснейшим делом он занимается, изучая изотопы благородного газа аргона на масс-спектрометре в отделе, которым руководит лауреат Ленинской премии Э.К. Герлинг в ЛАГЕДе (Лаборатория геологии докембрия). Он пригласил нас с Э.М. Прасоловым на экскурсию, так как уверял, что если мы все это сами увидим, то обязательно захотим изучать ИЗОТОПЫ на МАСС-СПЕКТРОМЕТРЕ

Масс-спектрометр располагался в большой комнате, где вдоль стен стояли стеклянные, заполненные ртутью (около литра) приборы, которые, как было сказано, называются приборами типа Хлопина-Герлинга и предназначены для выделения, очистки и измерения аргона с последующим переводом его в стеклянную ампулу. Ампулы отпаивались от этого прибора с помощью стеклодувной горелки и сдавались на масс-спектрометр для определения изотопного состава, т.е. отношения ${ }^{40} \mathrm{~A} Г{ }^{36}$ Аг. МАСС-СПЕКТРОМЕТР стоял напротив окна, и молодой сотрудник Г. Ашкинадзе заливал в него жидкий кислород! Белый пар поднимался к потолку, и на фоне окна все выглядело, как у средневековых алхимиков. И.Н. Толстихин говорил, что Э.К. Герлинг изобрел способ определения абсолютного возраста горных пород по соотношению аргона и калия и был удостоен за это Ленинской премии. Сам И.Н. Толстихин работал тогда над кандидатской диссертацией. Тема его работы была посвящена изотопам аргона в природных газах, У нас в стране этим пока никто не занимался, а за рубежом много уже было сделано и надо было догонять. Необходимые для анализа газы получали благодаря контактам со ВСЕГЕИ и ВНИГРИ, где отбор газов в это время был налажен.

Во ВНИГРИ (Всесоюзный нефтяной научно-исследовательский геологоразведочный институт) была Газовая лаборатория. Они собирались покупать масс-спектрометр, чтобы наладить анализы изотопов аргона. На Литейном проспекте, где располагался главный корпус ВНИГРИ, был также сектор Гелия, сотрудники которого ежегодно осуществляли экспедиции в разные уголки страны и отбирали пробы газов из месторождений углеводородов (УВ) и других объектов. Сектор гелия 
возглавляла тогда В.П. Якуцени. Она была заинтересована в прогрессе геохимии природных газов с применением изотопных методов и добивалась места для аспиранта, темой диссертационной работы которого должна была стать изотопия благородных газов. После посещения ВНИГРИ это место было предложено мне. Я стал очным аспирантом ВНИГРИ, моим научным руководителем согласился быть Ю.А. Шуколюков. Э.М. Прасолов стал сотрудником Газовой лаборатории ВНИГРИ, заведующей которой была 3.Н. Несмелова (ученица А.А. Черепенникова, который эту лабораторию и создал). Все это происходило летом 1966 г.

Начальные навыки обращения с изотопами Э.М. Прасолов и я получили в ЛАГЕДе. Г. Ашкинадзе показал нам, как надо запускать масс-спектрометр, как находить нужную массу, как брать отсчет высоты пиков ${ }^{40} \mathrm{~A} г,{ }^{36} \mathrm{~A} г$, как вскрывать (раздавливать в вакууме) стеклянные ампулы с чистыми препаратами аргона, как перемежать пробы и эталон (аргон из воздуха) и, опираясь на измерения эталона, рассчитывать изотопный состав аргона в пробах. Пока не было масс-спектрометра в Газовой лаборатории ВНИГРИ, мы выполнили в ЛАГЕДе около 50 анализов изотопов аргона из препаратов (запаянные ампулки с чистым аргоном), приготовленных в Газовой лаборатории ВНИГРИ из природных газов.

Работа на масс-спектрометре в ЛАГЕДе была для меня коротким эпизодом. Тогда (вторая половина 1966 г. и начало 1967 г.) я осваивал стеклянный, ртутный прибор типа Хлопина-Герлинга, на котором до этого И.Н. Толстихин обрабатывал газовые пробы, т.е. определял концентрации гелия и аргона и приготавливал чистые препараты этих благородных газов для последующих анализов их изотопного состава на масс-спектрометрах. Кандидатскую диссертацию И.Н. Толстихин защитил в 1966 г. Она была посвящена, как упоминалось, изотопам аргона, но, что показательно, он на всякий случай собирал (в 1964-65 гг.) и препараты гелия, имея в виду последующую изотопию гелия. «Научимся измерять изотопы гелия на масс-спектрометре, а коллекция уже готова! 30-40 анализов на этом, практически девственном поприще - и вот готовая диссертация!» - так тогда рассуждал И.Н. Толстихин.

Какой именно масс-спектрометр надо использовать для анализов изотопов гелия, было пока не ясно, несомненным же было то, что нужен будет эталон. Приготовлением его мы и занялись. Предполагалось, что, как и для аргона, эталоном будет гелий из воздуха. На заводе «Красный Автоген» путем глубокого охлаждения воздуха получали жидкий кислород и жидкий азот, а неконденсирующийся остаток обогащался гелием. Вот этот остаток в количестве примерно 5 л. и был любезно предоставлен администрацией завода для наших опытов. Этот остаток состоял из азота, неона и гелия. В ЛАГЕДе мы пропустили его через активированный уголь, замороженный жидким кислородом, и тем самым освободили от азота. Чистая же гелий-неоновая смесь (соотношение Не/ $\mathrm{Ne}$ около 0.3) была увезена в Физико-технический институт (ФТИ) им А.Ф. Иоффе, где неон был выморожен на жидком гелии. Получилась пробирка объемом около 1 л. с чистым воздушным гелием под давлением около 1 мм ртутного столба. Она имела отросток, снабженный усиком-носиком, который можно было разбить в вакууме, с тем, чтобы вскрыть эталон (на кончик усика-носика помещался железный цилиндрик и после получения высокого вакуума во внешней системе, этот цилиндрик приподнимался магнитом и бросался на кончик, который и разрушал усик-носик). Внешняя система имела гребёнку на 100 ампул, в которые и распределялся эталон. Ампулы отпаивались от гребёнки, и каждая из них в дальнейшем была эталоном при анализе проб [3]. Пока мы этим занимались, вышла статья в Докладах АН, где сотрудники ФТИ сообщали об изотопах гелия в материалах, заброшенных на некоторое время в верхние слои атмосферы, где они обогатились гелием с очень высоким отношением ${ }^{3} \mathrm{He} /{ }^{4} \mathrm{He}$. Анализы были выполнены в ФТИ им. А.Ф. Иоффе на магнитном-резонансном масс-спектрометре (МРМC) в лаборатории проф. Б.А. Мамырина. И.Н. Толстихин договорился с Б.А. Мамыриным о встрече, в результате которой возникло сотрудничество. Б.А. Мамырин познакомил нас с Г.С. Ануфриевым, прочитал нам лекцию об устройстве МРМС, и мы стали осваивать этот новый для нас прибор для того, чтобы понять, можно ли будет измерять гелий земного происхождения. 
Сейчас уже известно [4], что соотношение изотопов гелия в природе занимает диапазон в 10 порядков - от 1 до Е-10, и весь этот диапазон занят. Грубо говоря, для космических объектов от 1 до Е-4, а для земных вниз до Е-10 (в урановых минералах).

К 1967 г. имелась уже довольно обширная литература об изотопах гелия в метеоритах. Уже был открыт в метеорите Старое Песьяное Э.К. Герлингом и Л.К. Левским первозданный гелий (этот метеорит был им рекомендован для изучения В.В. Чердынцевым), а вот для материалов земного происхождения данных было очень мало. Американский физик А.О. Нир в 1948 г. определил примерный изотопный состав гелия воздуха (его значение ${ }^{3} \mathrm{He} /{ }^{4} \mathrm{He}=1.2 \mathrm{E}-6$ довольно близко к принятому сейчас $\left.{ }^{3} \mathrm{He} /{ }^{4} \mathrm{He}=1.38 \mathrm{E}-6\right)$. Он установил, что для гелия, выделенного из сподумена, отношение ${ }^{3} \mathrm{He} /{ }^{4} \mathrm{He}$ в 10 раз выше воздушного, что объяснялось наработкой ${ }^{3} \mathrm{He}$ на легком изотопе лития $\left({ }^{6} \mathrm{Li}+\mathrm{n} \rightarrow{ }^{4} \mathrm{He}+\mathrm{T} \rightarrow{ }^{3} \mathrm{He}\right.$ ). А для гелия природных газов (около десятка проб) в 10-100 раз ниже, т.е. находятся на уровне Е-7-Е-8. В нашей стране столь низкие отношения были измерены Э.К. Герлингом на циклотроне для двух образцов (воздух и природный газ), а на масс-спектрометре подобных измерений не было. Масс-спектрометр (МРМС), который мы осваивали, был построен Б.Н. Шустровым [5]. В этом приборе для получения высокого разрешения использовался модулятор напряжения, меняющий скорость влетающих в него ионов по синусоидальному закону, причем частота синусоиды подбиралась так, чтобы ионы с восстающего склона синусоиды второй раз влетали в этот же модулятор ниспадающим склоном, и тогда синусоидальная «размазанность» трансформировалась в точечный пакет ионов, что и обеспечивало высокое разрешение. Камера масс-спектрометра с источником ионов, модулятором и щелями целиком помещалась между полюсами постоянного магнита, а напряженность магнитного поля регулировалась шунтом (надо было вручную поворачивать колесо вроде «шоферской баранки» или корабельного штурвала).

К 1967 г. Б.Н. Шустров уже перешел в другой отдел и мы около МРМС возились втроем: Г.С. Ануфриев, И.Н. Толстихин и я под руководством Б.А. Мамырина. По предложению И.Н. Толстихина была выполнена некоторая модернизации. Во-первых, был встроен второй коллектор для регистрации ${ }^{4} \mathrm{He}$, что обеспечило одновременную регистрацию ${ }^{4} \mathrm{He}$ и ${ }^{3} \mathrm{He}$. А во-вторых, внутри камеры был помещен газопоглотитель - то, что сейчас называют ТСН (титановый сублимационный насоc), охлаждаемый жидким азотом, и это обеспечило поддержание высокого вакуума в запертой камере. Мы довольно долго подбирали режимы работы всех узлов МРМС, пытаясь при напуске нашего эталона, т.е. гелия из воздуха без неона, разглядеть сигнал от ${ }^{3} \mathrm{He}$ рядом с фоновой водородной массой $(\mathrm{HHH}+\mathrm{HD})$ и уже были близки к выводу, что ничего не получится. Фоновая масса от HНH+HD есть, хоть в открытой камере, хоть в закрытой, ее интенсивность падает, если ТСН охлаждается жидким азотом, а вот рядом с ней ничего не появляется, когда в камеру напускается гелий. ${ }^{4}$ Не на новом (встроенном) коллекторе регистрируется, а ${ }^{3}$ Не нет и нет. Но потом все ж, уже поздно вечером удачный режим был найден и рядом с резко выросшим водородом возник пик ${ }^{3} \mathrm{He}$. Интенсивности ${ }^{4} \mathrm{He}$ и ${ }^{3} \mathrm{He}$ для эталона были записаны в журнал, камера поставлена на откачку (эталон удален). Вторым образцом был товарный гелий Сосногорского ГПЗ. Он был напущен так, чтобы интенсивность ${ }^{4} \mathrm{He}$ была соизмерима с предыдущей от эталона, а на месте довольно высокого пика ${ }^{3}$ Не от эталона находился крохотный, но вполне измеряемый, гелий-3 от этого образца. Отсчеты гелия-4 и гелия-3 были записаны в журнал и из простой арифметической пропорции было вычислено отношение ${ }^{3} \mathrm{He} /{ }^{4} \mathrm{He}$ для товарного гелия. На тот момент для эталона было принято значение, приведенное в А.О. Ниром для воздушного гелия (1.2 Е-6) и для товарного (баллонного) гелия получилось отношение 2Е-8. Всё это случилось в начале 1968 г. Энтузиазм был большой, все были очень рады полученным результатам.

Первым делом мы прогнали коллекцию (запаянные ампулы с чистым гелием), которую И.Н. Толстихин предусмотрительно приготовил (на всякий случай, выше это уже отмечалось) при обработке газовых проб, составивших основу его кандидатской диссертации по изотопам аргона. Газовая лаборатория ВНИГРИ в то время была основательно занята контрольными анализами проб сектора гелия. Министерство геологии, к которому относилось ВНИГРИ, этот сектор и создало, чтобы точно знать состояние сырьевой базы этого важного стратегического элемента. В.П. Якуцени 
обобщила литературные данные, написала книгу «Геология гелия» [6], защитила докторскую диссертацию, а рядовые сотрудники каждый год проводили полевые работы и отбирали пробы газов из месторождений углеводородов и других газов. Надо сказать, что в то время все подземные газовые залежи характеризовались по химическому составу и содержание гелия приводилось в обязательном порядке. Пробы сотрудников сектора гелия, проанализированные в Газовой лаборатории, давали независимую информацию о содержании гелия. Как правило, она совпадала с данными региональных лабораторий, а в случае расхождений выяснялись причины и добивались правильного значения. Сектор гелия отвечал за достоверность запасов гелия в СССР. Но в этом секторе велась и научная работа, для которой были нужны изотопы аргона. В Газовой лаборатории ВНИГРИ пробы анализировались и на аргон и часть его собиралась в стеклянную ампулу и отпаивалась стеклодувной горелкой. Эти препараты поступали на масс-спектрометр МС-10 Э.М. Прасолову и исследовались на соотношение ${ }^{40} \mathrm{~A} г{ }^{36}$ Аг. Возникла идея, что из этих проб можно собирать и гелий, как это делал И.Н. Толстихин четырьмя годами раньше в ЛАГЕДе. З.Н. Несмелова (заведующая Газовой лаборатории ВНИГРИ) пошла навстречу нашей просьбе и поручила лаборантам Шебалиной Г.М. и Ивановой О.И., обслуживающим установки, где определялись концентрации Не и Аг и готовились ампулки с чистым аргоном, собирать и гелий в ампулы, отпаивать их и тем самым обеспечивать нас в ФТИ работой. Первые анализы в виде таблицы была передана в сектор Гелия (Тихомирову В.В. - геологу, отобравшему пробы). Результаты получили одобрение, В.П. Якуцени ввела раздел про изотопы гелия в тему сектора, но сделала замечание, что пробами надо охватить не только Среднюю Азию (В.В. Тихомиров как раз привез ее оттуда). Так как в Газовой лаборатории ВНИГРИ хранились ранее изученные пробы, из них были намечены около 150 штук для анализов на изотопы гелия (эта подборка, т.е. оценка представительности «старых» проб была осуществлена 3.Н. Несмеловой и В.П. Якуцени). Эта выборка охватывала уже всю территорию СССР (ДнепровскоДонецкую впадину, Предкавказье, Русскую платформу, Тимано-Печерскую провинцию, Мангышлак, где были открыты месторождения Узень и Жетыбай и сотрудники ВНИГРИ стали лауреатами Ленинской премии), Западная и Восточная Сибирь, Якутия). Я забирал приготовленные ампулы с чистым гелием (точнее с чистой гелий-неоновой смесью) и в ФТИ они превращались в таблицы значений отношения $3 \mathrm{He} / 4 \mathrm{He}$. Но однажды, вот он случай (Бог - изобретатель), придя в Газовую лабораторию ВНИГРИ за очередной партией ампул, я узнал, что работа с намеченной коллекцией остановлена. Мне сказали, что 3.Н. Несмелову геолог из ВСЕГЕИ (Н.В. Альбинский) попросил проанализировать его коллекцию побыстрее и не определять в ней гелий. Так как новых ампул с препаратами гелия для изотопных анализов не было, я собрался уже было уходить, что называется «не солоно хлебавши», как вдруг Г.М. Шебалина сказала, что может собрать гелий из трех последних проб Н.В. Альбинского (на всякий случай). Я спросил, хватит ли ампул для обязательных, намеченных ранее, проб и получив утвердительный ответ, согласился. В следующий «заход» я забрал десяток ампул, среди которых были и эти три, как оказалось, из гидротерм Курильских островов. Они были проанализированы 4 и 11 июня, показали значения близкие к тем, что сейчас называется MORB. И.Н. Толстихин написал статью, ознакомил меня, переговорил с Н.В. Альбинским, получил от него разрешение на публикацию этих данных без претензий на авторство / соавторство и предъявил этот текст сотрудникам ФТИ (Б.А. Мамырину и Г.С. Ануфриеву). Борис Александрович обратился к директору ФТИ академику Б.П. Константинову, который определил порядок фамилий в авторском списке и рекомендовал к публикации в Докладах АН. Журнал принял ее в июле 1968 г., а в мае 1969 г. она вышла. В статье был рисунок с гистограммой значений ${ }^{3} \mathrm{He} /{ }^{4} \mathrm{He}$ для всех, проанализированных к концу июня 1968 г. проб, и значения для метеоритов с первичным гелием (Старое Песьяное и др.).

В августе-сентябре 1968 г. в Ленинграде находился канадский ученый Х. Крейг, специалист по изотопной геохимии химически активных элементов $\left(\mathrm{N}_{2}, \mathrm{~S}, \mathrm{C}\right)$, и знакомился с состоянием изотопных исследований в СССР. Он посетил ЛАГЕД и потом оказался у нас в лабораторном корпусе ВНИГРИ. Кроме Газовой лаборатории, о которой рассказано выше, имелась и изотопная лаборатория. В этой лаборатории И.М. Адельберг исследовал вариации изотопного состава углерода в составе углеводородных природных газов и нефтей. Из газовых проб препараты для его анализов гото- 
вились в Газовой лаборатории, в той же самой комнате со стеклянными, ртутными установками, на которых как раз и работали Г.М. Шебалина и О.И. Иванова, изготавливая ампулы с аргоном и гелием. Я оказался в этой комнате, и вместе с Э.М. Прасоловым мы самым подробным образом рассказали канадскому ученому, как и что тут изучается в отношении изотопов БЛАГОРОДНЫХ ГАЗОВ (Не и Аг). Перед расставанием я подарил ему фотографию с рисунком из статьи, представленной в Доклады АН. Дальнейшее показало, что этот рисунок был предъявлен В.Б. Кларку, который анализировал океаническую воду. Уже ближе к концу 1968 г. от В.Б. Кларка на мое имя пришла толстая бандероль с копиями научных статей про вариации изотопных составов углерода, серы и рукопись с данными про изотопы гелия в воде Тихого океана. Была приложена краткая записка с просьбой прислать ему копию нашей статьи про «АНОМАЛЬНЫЙ ИЗОТОПНЫЙ СОСТАВ ГЕЛИЯ В ВУЛКАНИЧЕСКИХ ГАЗАХ» [2]. Но эта статья вышла только в мае 1969 г., а посылать рукопись я не считал себя в праве. Таким образом, очевидно то, что, сдавая свою статью для публикации в журнал, В.Б. Кларк наш результат уже знал. Его статью приняли в мае 1969 г., как выше это уже упоминалось. Все это дает нам право утверждать что первый опыт (который не опыт) был сделан в СССР, a В.Б. Кларк своим вторым опытом перевел явление в разряд закона (кстати, его 20 \% превышение отношения ${ }^{3} \mathrm{He} /{ }^{4} \mathrm{He}$ над воздухом выглядит очень бледно по сравнению с нашим 10-кратным). И вторым опытом, с нашей точки зрения, следовало бы считать опыт с подводным базальтом А.Я. Крылова [1]. Б.А. Мамырину, И.Н. Толстихину, Г.С. Ануфриеву, И.Л. Каменскому и Л.В. Хабарину выданы ДИПЛОМЫ об ОТКРЫТИИ мантийного гелия за №253.

Автор выражает глубокую благодарность за помощь в составлении этого текста Г.С. Ануфриеву и А.А. Аведисян.

\section{Литература}

1. Крылов А.Я., Мамырин Б.А., Хабарин Л.В. и др. Изотопы гелия в породах дна океанов // Геохимия. 1974. № 8. C. 1224-1226.

2. Мамырин Б.А., Толстихин И.Н., Ануфриев Г.С. и др. Аномальный изотопный состав гелия в вулканических газах // Докл. АН. 1969. Т. 184. № 5. С. 1197-1200.

3. Мамырин Б.А., Ануфриев Г.С., Каменский И.Л. и др. Определение изотопного состава гелия в атмосфере // Геохимия. 1970. № 6. С. 721-730.

4. Толстихин И.Н. Изотопная геохимия аргона, гелия и редких газов. Л.: Наука. 1986. 200 с.

5. Шустров Б.Н. Новая схема импульсного магнитного масс-спектрометра высокой разрешающей силы // Журнал технической физики. 1960. Т. 30. С. 860-864.

6. Якуцени В.П. Геология гелия. Л.: Недра. 1968. 223 с.

7. Honda M., Patterson D.B. Systematic elemental fractionation of mantle-derived he lium, neon and argon in midoceanic ridge glasses // Geochim. Cosmochim. Acta. 1999. V. 63. N 18. P. 2863-2874.

8. Kamensky I.L. History of discovery of mantle helium in Russia (reminiscences) // Chinese Sci. Bull. 1998. V. 43. P. 62.

9. Moreira M. Noble gas constraints on the origin and evolution of Earth's volatiles // Geochem. Perspectives. 2013. V. 2. N 2. $403 \mathrm{p}$. 